University of Wollongong

Research Online

Faculty of Engineering and Information

Faculty of Engineering and Information

Sciences - Papers: Part A

Sciences

$1-1-2016$

\title{
Effective utilization of available PEV battery capacity for mitigation of solar PV Impact and grid support with integrated V2G functionality
}

Md Jan E Alam

University of Wollongong, mjealam@uowmail.edu.au

Kashem M. Muttaqi

University of Wollongong, kashem@uow.edu.au

Danny Sutanto

University of Wollongong, soetanto@uow.edu.au

Follow this and additional works at: https://ro.uow.edu.au/eispapers

Part of the Engineering Commons, and the Science and Technology Studies Commons

Research Online is the open access institutional repository for the University of Wollongong. For further information contact the UOW Library: research-pubs@uow.edu.au 


\title{
Effective utilization of available PEV battery capacity for mitigation of solar PV Impact and grid support with integrated V2G functionality
}

\begin{abstract}
Utilizing battery storage devices in plug-in electric vehicles (PEVs) for grid support using vehicle-to-grid (V2G) concept is gaining popularity. With appropriate control strategies, the PEV batteries and associated power electronics can be exploited for solar photovoltaic (PV) impact mitigation and grid support. However, as the PEV batteries have limited capacity and the capacity usage is also constrained by transportation requirements, an intelligent strategy is necessary for an effective utilization of the available capacity for V2G applications. In this paper, a strategy for an effective utilization of PEV battery capacity for solar PV impact mitigation and grid support is proposed. A controllable charging/discharging pattern is developed to optimize the use of the limited PEV battery capacity to mitigate PV impacts, such as voltage rise during midday or to support the evening load peak. To ensure an effective utilization of the available PEV battery capacity when used for travel (which is the main usage of the PEVs) or when interventions in the charging operation is caused by passing clouds, a strategy for dynamic adjustments in PEV charging/discharging rates is proposed. The effectiveness of the proposed strategy is tested using a real distribution system in Australia based on practical PV and PEV data.
\end{abstract}

\section{Keywords}

impact, grid, support, integrated, v2g, functionality, available, pev, effective, battery, utilization, capacity, mitigation, solar, pv

\section{Disciplines \\ Engineering | Science and Technology Studies}

\section{Publication Details}

M. J.E. Alam, K. M. Muttaqi \& D. Sutanto, "Effective utilization of available PEV battery capacity for mitigation of solar PV Impact and grid support with integrated V2G functionality," IEEE Transactions on Smart Grid, vol. 7, (3) pp. 1562-1571, 2016. 


\title{
Effective Utilization of Available PEV Battery Capacity for Mitigation of Solar PV Impact and Grid Support with Integrated V2G Functionality
}

\author{
M. J. E. Alam, Member, IEEE, K. M. Muttaqi, Senior Member, IEEE and D. Sutanto, Senior Member, \\ IEEE
}

\begin{abstract}
Utilizing battery storage devices in Plug-in Electric Vehicles (PEV) for grid support using Vehicle-to-Grid (V2G) concept is gaining popularity. With appropriate control strategies, the PEV batteries and associated power electronics can be exploited for solar photovoltaic (PV) impact mitigation and grid support. However, as the PEV batteries have limited capacity and the capacity usage is also constrained by transportation requirements, an intelligent strategy is necessary for an effective utilization of the available capacity for V2G applications. In this paper, a strategy for an effective utilization of PEV battery capacity for solar PV impact mitigation and grid support is proposed. A controllable charging/discharging pattern is developed to optimize the use of the limited PEV battery capacity to mitigate PV impacts, such as voltage rise during midday, or to support the evening load peak. To ensure an effective utilization of the available PEV battery capacity when usedfor travel (which is the main usage of the PEVs)or when interventions in the charging operation is caused by passing clouds, a strategy for dynamic adjustments in PEV charging/discharging rates is proposed. The effectiveness of the proposed strategy is tested using a real distribution system in Australia,based on practical PV and PEV data.
\end{abstract}

Index Terms-Plug-in Electric Vehicles (PEV), Vehicle-toGrid (V2G), solar photovoltaic impact, distribution network support, charging/discharging control.

\section{NOMENCLATURE}

$k, \Delta t$

$I_{\mathrm{Chg}}^{\mathrm{PEV}}$,

$I_{\text {Chg-max }}^{\text {PEV }}$,

$\omega_{\mathrm{Chg}}^{\mathrm{PEV}}$

$\mathrm{SoC}^{\mathrm{PEV}}$

$\mathrm{SoC}_{L L}$

$\mathrm{SoC}_{\max }^{\mathrm{PEV}}$

$C_{\text {Chg-a }}, C_{\text {Chg- }}$
Index for time instant, and time difference between two time instants, respectively.

PEV charging current, the maximum PEV charging current, and the rate of change of PEV charging current, respectively.

PEV SoC, SoC at the start of the charging period, and the maximum allowable $\mathrm{SoC}$ level, respectively.

Points of the SoC curve for controlling the

This work is supported by the Australian Research Council (ARC) and Essential Energy Linkage Grant, LP100100618.

Mr. M. J. E. Alam, A/Prof. Kashem M. Muttaqi, and Prof. Danny Sutanto are with Australian Power Quality and Reliability Center, School of Electrical Computer and Telecommunications Engineering, University of Wollongong, NSW 2522, Australia. (e-mail: mjea982@uowmail.edu.au, kashem@uow.edu.au, soetanto@uow.edu.au).

\begin{tabular}{|c|c|}
\hline${ }_{\mathrm{b}}, C_{\mathrm{Chg-a}}, C_{\mathrm{Chg}-}$ & $\begin{array}{l}\text { charging and discharging patterns, } \\
\text { respectively. }\end{array}$ \\
\hline$K_{\text {Chg-a }}, K_{\text {Chg-b }}$ & $\begin{array}{l}\text { User defined parameters for determining } \\
\text { the charging patterns. }\end{array}$ \\
\hline$I_{\mathrm{Dsch}}^{\mathrm{PEV}}$ & PEV discharging current, the maximum \\
\hline$I_{\text {Dsch-max }}^{\mathrm{PEV}}$ & $\begin{array}{l}\text { PEV discharging current, and the rate of } \\
\text { change of PEV discharging current, }\end{array}$ \\
\hline$\omega_{\mathrm{Dsch}}^{\mathrm{PEV}}$ & respectively. \\
\hline$T_{\text {Chg }}, T_{\text {Dsch }}$ & $\begin{array}{l}\text { Period for charging and discharging, } \\
\text { respectively. }\end{array}$ \\
\hline$F_{\text {Time }}$ & Time conversion factor. \\
\hline $\begin{array}{l}C^{\mathrm{PEV}}, \\
V_{\text {batt }}^{\mathrm{PEV}}\end{array}$ & Battery capacity and battery voltage. \\
\hline$P_{\mathrm{Imp}}, P_{\mathrm{PS}}$ & $\begin{array}{l}\text { Power import from grid and the threshold } \\
\text { for peak shaving, respectively. }\end{array}$ \\
\hline $\mathrm{SoC}_{\mathrm{HH}}$ & SoC at the start of the discharging period, \\
\hline $\mathrm{SoC}_{\min }^{\mathrm{PEV}}$ & $\begin{array}{l}\text { minimum allowable SoC level, and } \\
\text { minimum SoC level specified for PEV }\end{array}$ \\
\hline $\mathrm{SoC}_{\text {min-spec }}^{\mathrm{PEV}}$ & operation, respectively. \\
\hline$l_{\text {travel }}, \mathrm{FE}_{\mathrm{PEV}}$ & Length of travel, and PEV fuel economy. \\
\hline$I_{\text {Chg-adj }}^{\text {PEV }}$ & Adjusted PEV charging rate. \\
\hline $\begin{array}{l}\mathrm{SoC}_{\mathrm{ref}}^{\mathrm{PEV}}, \\
\mathrm{SoC}_{\mathrm{act}}^{\mathrm{PEV}}\end{array}$ & Reference and actual SoC, respectively. \\
\hline
\end{tabular}

\section{INTRODUCTION}

$\mathrm{V}$ 2Gconcept is becoming increasingly attractive for supporting the electric grid [1-9] from the stored energy in Plug-in-Electric-Vehicle (PEV) batteries. PEVs are typically charged from the grid when people come back from work in the evening. Such collective charging can impose an additional burden [10-12]on the distribution system. However, with an increasing level of solar PV penetration in the distribution networks, this situation could be exploited as an opportunity to support a high level of solar PV penetration. Solar PV resources produce power at the peak level during midday. At this time, the residential feeder demand is typically lower compared to the evening peak. The PV output exceeding the local demand at the point of common coupling (PCC) of the PV inverter has to be injected into the grid and 
will produce a reverse directional power flow and voltage rise. These issues have been reported in literature $[13,14]$ as major concerns in increasing the PV penetration level. Active power curtailment has been proposed in [15] to limit the voltage rise problem which makes the overall economics of a solar PV installation project less attractive. The consumption of reactive power has been proposed to reduce the voltage rise problem in [16], however this will create a high reactive power flow and increased power loss in the feeder. Moreover, as distribution networks are constructed using different combinations of overhead and underground cables with high $\mathrm{R} / \mathrm{X}$ ratio, this method may not be very effective due to the low sensitivity of voltage with reactive power. The integration of storage devices with solar PV systems can be an attractive solution in this case to store the surplus energy from solar PV by charging the batteries.

The number of electric vehicles sold each year is increasing due to the variety of types and models brought to market by automobile manufacturers. Although commercial electric vehicles are not designed with comprehensive V2G functionality at the moment, this may be available as an optional feature in near future at extra cost. Studies show that these vehicles are on travel only during a small portion of the day and the rest of the time these vehicles are in parked position[17]. The statistics presented in [18] show that the probability of a PEV to be parked anywhere during the midday period is over 0.9 and the probability for it to be parked at home is over 0.5 for urban and rural weekday or weekend day. Further, it is likely in the developed countries that there are two cars in a household, one of which may be parked at home most of the time. PEVs can be plugged into the grid using a bidirectional charger while in a parked position to act as a storage device for solar PV systems. Similar with the stationary storage devices used with PV inverters, the PEVs can act to limit the voltage rise problem at midday by consuming power to charge the PEV battery and hence can contribute to the increase of PV penetration level in the distribution grid which would otherwise be limited by the high PV penetration problems. The stored energy in those PEV batteries can support the distribution feeder during evening peak by injecting power to the local PCC so that less power is imported through the feeder to reduce the stress on the grid. However, it is to be noted that the usage of PEV battery for the grid ancillary support can contribute to the loss of its cycle life and may cause a need for an early battery replacement.

The effectiveness of the V2G concept for mitigating PV impacts and grid support will depend on how the PEV battery capacity is utilized. The reverse power flow and voltage rise impact of PV will vary mainly depending on the sun irradiance level and the load demand (active and reactive power), and will be at the most severe state in the midday when PV power is at the peak level and load demand is the lowest. Therefore, it would be more effective to charge the PEV battery at the highest rate in the midday and at lower rates before and after the midday as compared to charging with a constant rate all the time. Similarly, it would be wise to discharge the PEV battery at the highest rate during the maximum peak load period and at lower rates before and after. As the PEV battery will have a limited capacity, the charging/discharging rates will have to be such that the capacity is neither left unused nor finished earlier than the intended period of operation. The use of a separate energy storage device for the mitigation of PV and PEV impacts is reported in $[19,20]$. Instead of using a separate battery, PEV battery is used in [21] for mitigation of voltage rise caused by PV. In a previous work [22], authors have developed a strategy for the effective usage of the battery capacity integrated with rooftop PV systems for PV impact mitigation and evening peak load support. As the PEV battery capacity is also limited in nature and can also experience intermittencies due to incidental travels, it would be worthwhile to develop a control strategy for effective usage of PEV batteries for PV applications.

The contribution of this paper is to develop a wise strategy for charging/discharging of the PEV battery to effectively exploit the opportunities of the V2G concept for mitigating the voltage rise impact of solar PV and for providing the evening peak load support. The main contributions of the proposed strategy are: (i) to make the PEV batteries consume the highest amount of surplus PV power when the PV impact is most severe;(ii)to generate the highest amount of power from the PEV batteries when the maximum demand appear during the evening peak; and, (iii)the dynamic adjustment feature of the PEV charging/discharging currents to account for the interventions in charging/discharging operation caused by travels and passing clouds to ensure an effective utilization of the available battery capacity. Also, the paper proposes an intelligent strategy for the returning vehicles after work to be charged in the late night/early morning in a controlled manner to coincide the PEV charging load with the customer minimum load so that stress on the distribution system is reduced.

Section II of the paper describes charging/discharging rate determination method using the mathematical formulation of capacity constraints, usage pattern, and charging/discharging rate adjustment of the PEV battery. Section III tests the performance of the proposed strategy using a real distribution network model. Section IV concludes the paper summarizing the overall contributions of the paper.

\section{PEV BATTERY CONTROL STRATEGY FOR PV IMPACT MITIGATION AND GRID SUPPORT}

A conceptual diagram showing a parked PEV connected to a point of common coupling (PCC) of a PV system, household loads and the distribution grid is shown in Fig. 1(a). The surplus power from the PV system will be consumed by the PEV battery to mitigate the impacts of excess PV power, such as reverse power flow, voltage rise etc. The stored energy in the PEV battery can be used for grid support during grid peak load period, e.g., in the evening, and when no PV is present, e.g., during cloudy period. A number of PEVs connected to the feeder at the same time, as shown in Fig. 1(b), can bring considerable benefits for the whole feeder and upstream 
network in terms of voltage rise mitigation and voltage support. It is to be noted that at a given instant of time, all the PEVs in a feeder may not be present as they are out for travel as shown using dashed rectangles in Fig. 1(b). This would be the case particularly during the day time. However, the remaining amount of PEVs parked at home can still be used for PV impact mitigation.

As PEV battery capacity is limited in nature, a wise strategy to effectively utilize this limited capacity would be necessary for network support. A charging/discharging control strategy leading to an effective utilization of the PEV battery is developed below.

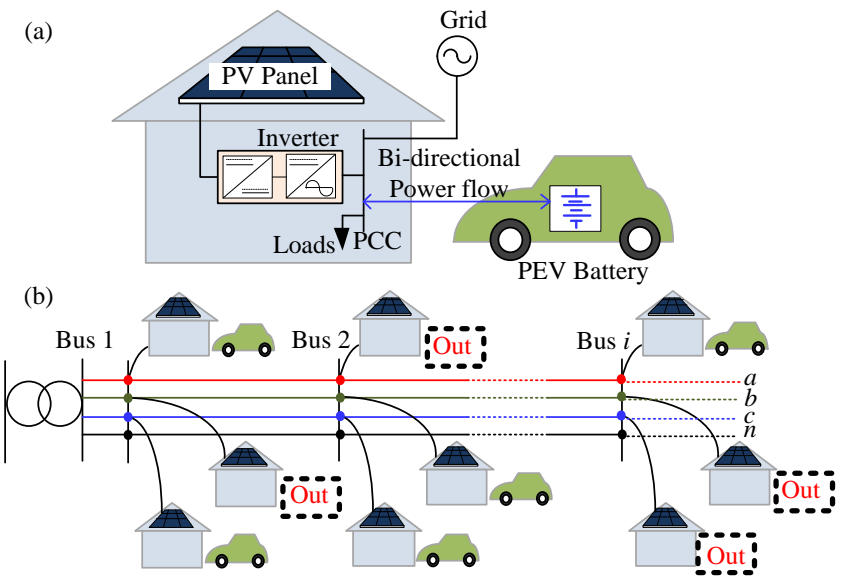

Fig. 1. PEV for PV impact mitigation and grid support. (a) Connection of a PEV with the PCC (b) A number of PEVs connected to the feeder.

\section{A. Determination of Charging/Discharging Rate for Effective Utilization of PEV Battery Capacity}

Assume that the PEV will have to be charged in $T_{\mathrm{Chg}}$ hours during the surplus PV power period over the day, as shown in Fig. 2(a). This period can be determined from the historical load and PV generation profile. The values of the PEV charging current are controlled during this period based on a user-defined pattern to effectively utilize the PEV battery capacity for PV impact mitigation. Typically, under a clearsky condition, PV output will reach its peak during the midday, increasing from a zero value at the sunrise and again will decrease to a zero value at the sunset. Therefore it would be wise to charge the PEV battery at a higher rate during the midday period as compared to the charging rates during the morning and afternoon periods. Fig. 2(b) shows a trapezoidal pattern is used to consider this scenario in the PEV charging current control. To ensure that the PEV battery capacity is not left unused or the battery is not overcharged, the PEV charging current is controlled at any given time instant $k$ according to (1).

$$
I_{\mathrm{Chg}}^{\mathrm{PEV}}(k)=\left\{\begin{array}{l}
I_{\mathrm{Chg}}^{\mathrm{PEV}}(k-1)+\omega_{\mathrm{Chg}}^{\mathrm{PEV}} \Delta t, \text { if } \operatorname{SoC}^{\mathrm{PEV}}(k-1) \leq C_{\mathrm{Chg}-\mathrm{a}} \\
I_{\mathrm{Chg}-\mathrm{PEV}}^{\mathrm{PEx}}, \text { if } C_{\mathrm{Chg}-\mathrm{a}}<\operatorname{SoC}^{\mathrm{PEV}}(k-1)<C_{\mathrm{Chg}-\mathrm{b}} \\
I_{\mathrm{CEg}}^{\mathrm{PEV}}(k-1)-\omega_{\mathrm{Chg}}^{\mathrm{PEV}} \Delta t, \text { if } \operatorname{SoC}^{\mathrm{PEV}}(k-1) \geq C_{\mathrm{Chg}-\mathrm{b}} \\
0, \text { if } \operatorname{SoC}^{\mathrm{PEV}}(k-1) \geq \operatorname{SoC}_{\max }^{\mathrm{PEV}}
\end{array}\right.
$$

where, $I_{\mathrm{Chg}}^{\mathrm{PEV}}$ is the PEV charging current (ampere); $\omega_{\mathrm{Chg}}^{\mathrm{PEV}}$ is the rate of change of charging current (ampere per time instant) to follow the user defined charging profile; $\Delta t$ is the time difference between two time instants; $\mathrm{SoC} \mathrm{CEV}^{\mathrm{PV}}$ is the state of charge of PEV battery; $C_{\mathrm{Chg} \text {-a }}$ and $C_{\mathrm{Chg} \text {-b }}$ are two thresholds of SoC (in per unit) specifying the shape of the user defined charging profile. The values of $I_{\mathrm{Chg} \text {-max }}^{\mathrm{PEV}}$ and $\omega_{\mathrm{Chg}}^{\mathrm{PEV}}$ can be determined from a system of non-linear equations given below in (2), developed based on the geometric relationships of the charging profile during the period $T_{\mathrm{Chg}}$ in Fig. 2(b). The amount of charge accumulated during the period when the charging rate increases from zero to the maximum value can be obtained using the expression of the area of a triangle. The upper expression in the right hand side of (2) is then obtained by equating this amount with the amount of charge obtained using points $C_{\mathrm{Chg} \text {-a }}$ and $\mathrm{SoC}_{\mathrm{LL}}$ on the SoC curve in Fig. 2(b). The amount of charge accumulated during the period when the charging rate is constant can be obtained using the expression of the area of a rectangle. The lower expression in the right hand side of (2) is then obtained by equating this amount with the amount of charge obtained using points $C_{\text {Chg-a }}$ and $C_{\text {Chg-b }}$ on the SoC curve in Fig. 2(b).

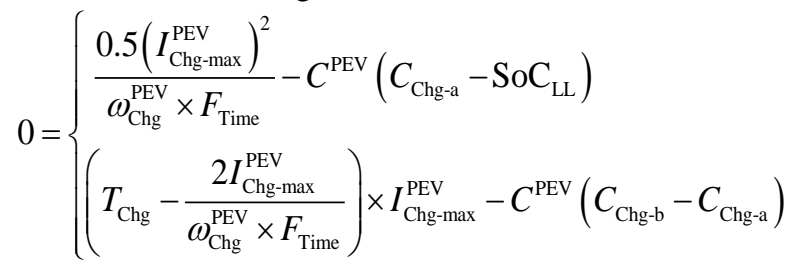

where, $\mathrm{SoC}_{\mathrm{LL}}$ is the $\mathrm{SoC}$ at the start of the charging operation; $C^{\mathrm{PEV}}$ is the capacity of the PEV battery in $\mathrm{Ah}, F_{\text {Time }}$ is a conversion factor to convert the unit of time to hour from the unit of time used in (1); if the unit of time in (1) is minute or second, $F_{\text {Time }}$ will be 60 or 3600 , respectively.
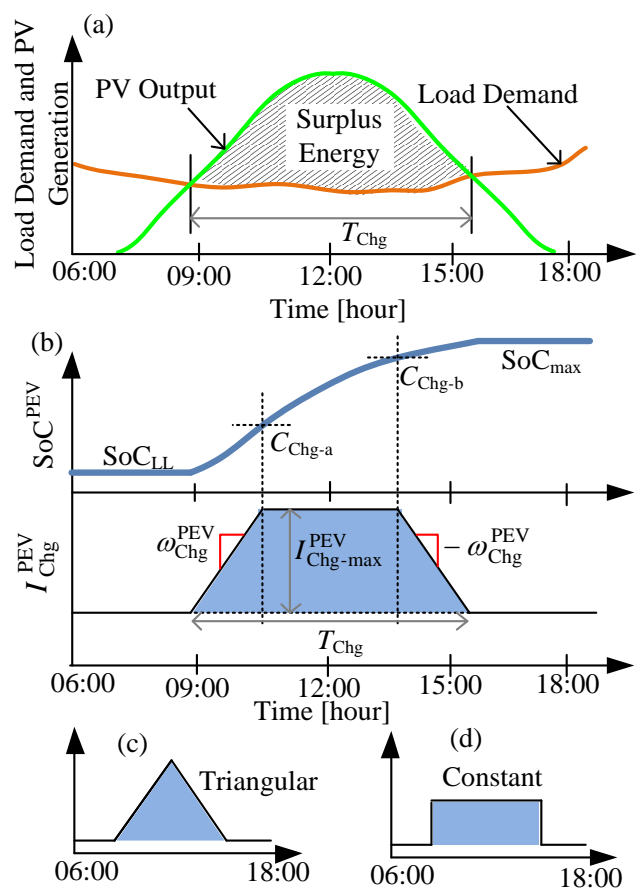

Fig. 2. Development of a PEV charging current control strategy (a) Load and PV generation profile (b) Control of PEV charging current in relation to PEV $\mathrm{SoC}$ (c) Triangular charging profile (d) Constant charging profile. 
The limits $C_{\text {Chg-a }}$ and $C_{\text {Chg-b }}$ are obtained using user defined parameters $K_{\text {Chg-a }}$ and $K_{\text {Chg-b }}$ respectively that sets the proportions of the available capacity of the PEV battery to be spent during the time when the charging rate is increasing and when the charging rate is constant, as given below.

$$
\begin{aligned}
& C_{\mathrm{Chg}-\mathrm{a}}=\mathrm{SoC}_{\mathrm{LL}}+\left(\mathrm{SoC}_{\max }^{\mathrm{PEV}}-\mathrm{SoC}_{\mathrm{LL}}\right) \times K_{\mathrm{Chg}-\mathrm{a}} \\
& C_{\text {Chg-b }}=C_{\mathrm{Chg} \text {-a }}+\left(\mathrm{SoC}_{\max }^{\mathrm{PEV}}-\mathrm{SoC}_{\mathrm{LL}}\right) \times K_{\mathrm{Chg}-\mathrm{b}}
\end{aligned}
$$

The user defined variables $K_{\text {Chg-a }}$ and $K_{\text {Chg-b }}$ can be used to control the charging profile patterns. The trapezoidal pattern in Fig. 2(b) is obtained using $K_{\text {Chg-a }}=0.25$, and $K_{\text {Chg-b }}=0.5$. The PEV charging profile can be switched to a triangular shape by setting $K_{\text {Chg-a }}=0.5$, and $K_{\text {Chg-b }}=0$, as shown in Fig. 2(c); a constant charging profile can be obtained by setting $K_{\text {Chg-a }}=$ 0.0 , and $K_{\text {Chg-b }}=1.0$, as shown in Fig. $2(\mathrm{~d})$.

Discharging of the PEV battery is performed for peak load support in the evening when PV power is not available, while retaining a limited capacity in case there is a need for travel. This limited capacity depends on the distance for which the PEV will need to be able to run before the next charging. A peak-shaving strategy is adopted for discharge operation where the PEV battery will inject power depending on the available capacity in the PEV battery. The discharging period can be obtained from a reference demand curve, as shown in Fig. 3(a), derived from historical demand curves of the customer household where the PEV will be plugged in.

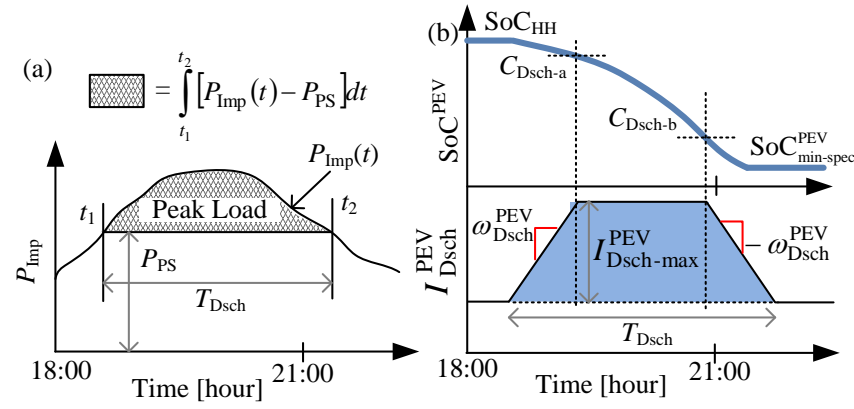

Fig. 3. Development of PEV battery discharge strategy (a) Determination of $T_{\text {dsch }}$ (b) Control of PEV discharging current in relation to PEV SoC.

If discharge operation is performed for $T_{\text {Dsch }}$ hours using a peak shaving mode, then the following expression will be true.

$$
\begin{aligned}
& \int_{t_{1}}^{t_{2}}\left[P_{\mathrm{Imp}}(t)-P_{\mathrm{PS}}\right] d t-C^{\mathrm{PEV}} \times\left(\mathrm{SoC}_{\mathrm{HH}}-\mathrm{SoC}_{\text {min-spec }}^{\mathrm{PEV}}\right) \times V_{\text {batt }}^{\mathrm{PEV}}=0 \\
& t_{2}-t_{1}=T_{\text {Dsch }},\left(P_{\mathrm{Imp}}(t)-P_{\mathrm{PS}}\right) \geq 0
\end{aligned}
$$

where, $P_{\operatorname{Imp}}$ is the power import from the grid by the load demand, $P_{\mathrm{PS}}$ is the threshold power for peak-shaving operation, $\mathrm{SoC}_{\mathrm{HH}}$ is the $\mathrm{SoC}$ at the start of the discharge period, $\mathrm{SoC}_{\text {min-spec }}^{\mathrm{PEV}}$ is the user specified minimum $\mathrm{SoC}$ of the PEV battery. The value of $P_{\mathrm{PS}}$ that satisfies (4) is used to derive $T_{\mathrm{Dsch}}$. To effectively utilize the PEV battery capacity in the discharge operation, the PEV discharge current is controlled in such a way that the highest discharging rate appears during the period of the maximum evening peak load, and lower in the periods before and after that, as shown in Fig, 3(b). At a given $k$-th instant, the discharge current is controlled as given below.

$$
I_{\mathrm{Dsch}}^{\mathrm{PEV}}(k)=\left\{\begin{array}{l}
I_{\mathrm{Dsch}}^{\mathrm{PEV}}(k-1)+\omega_{\mathrm{Dsch}}^{\mathrm{PEV}} \Delta t, \text { if } \operatorname{SoC}^{\mathrm{PEV}}(k-1) \geq C_{\mathrm{Dsch}-\mathrm{a}} \\
I_{\mathrm{Dsch}-m a x}^{\mathrm{PEV}}, \text { if } C_{\mathrm{Dsch}-\mathrm{a}}>\operatorname{SoC}^{\mathrm{PEV}}(k-1)>C_{\mathrm{Dsch}-\mathrm{b}} \\
I_{\mathrm{Dsch}}^{\mathrm{PEV}}(k-1)-\omega_{\mathrm{Dsch}}^{\mathrm{PEV}} \Delta t, \text { if } \operatorname{SoC}^{\mathrm{PEV}}(k-1) \leq C_{\mathrm{Dsch}-\mathrm{b}} \\
0, \text { if } \operatorname{SoC}^{\mathrm{PEV}}(k-1) \leq \operatorname{SoC}_{\text {min-spec }}^{\mathrm{PEV}}
\end{array}\right.
$$

The values of $I_{\text {Dsch-max }}^{\mathrm{PEV}}$ and $\omega_{\mathrm{Dsch}}^{\mathrm{PEV}}$ are obtained from a similar non-linear system of equation as given in (2) by replacing the parameters related to the charging operation with the parameters related to the discharging operation. The PEV battery overcharge limit $\mathrm{SoC}_{\max }^{\mathrm{PEV}}$ can be obtained from the manufacturer specified maximum limit. The value of $\mathrm{SoC}_{\text {min-spec }}^{\mathrm{PEV}}$ for a PEV battery will depend on how much energy will have to be retained for the travels before next charging opportunity. In this paper, the value of $\mathrm{SoC}_{\text {min-spec }}^{\mathrm{PEV}}$ is obtained using the distance for which the PEV will need to be able to run before the next charging, as given below.

$$
\mathrm{SoC}_{\text {min-spec }}^{\mathrm{PEV}}=\mathrm{SoC}_{\text {min }}^{\mathrm{PEV}}+\frac{l_{\text {travel }}+\mathrm{FE}_{\mathrm{PEV}}}{C^{\mathrm{PEV}} \times V_{\mathrm{batt}}^{\mathrm{PEV}}}
$$

where, $\mathrm{SoC}_{\mathrm{min}}^{\mathrm{PEV}}$ is the manufacturer specified minimum SoC, $l_{\text {travel }}$ is the travel length before the next charging including any incidental travel (to hospital, police station etc.) in $\mathrm{km}$, and $\mathrm{FE}_{\mathrm{PEV}}$ is the PEV fuel economy in $\mathrm{kWh} / \mathrm{km}$.

It is worth to consider that utilizing a PEV battery for customer load support using V2G functionality will increase the number of charging/discharging cycles and may impact the battery life.

\section{B. Adjustment of PEV Battery Charging/Discharging Current to Account for Intermittent Events}

PEV battery will be charged from surplus solar PV power which is practically intermittent due to the dependency on the solar irradiance level. If the solar irradiance is not available for a certain amount of time, the PEV battery cannot be charged. Also, if the PEV is used for any travel within the charging period, the PEV capacity will be depleted. To account for this, the charging rate will have to be adjusted during the periods when surplus PV power is again available. The adjustment of PEV battery charging current is performed based on a reference SoC profile that is obtained using (1). If there is a deviation between the reference $\mathrm{SoC}$ and actual $\mathrm{SoC}$, then adjustment is made to make up for the difference, as given in (7).

$$
\begin{aligned}
& I_{\mathrm{Chg}-\text {-adj }}^{\mathrm{PEV}}(k)=I_{\mathrm{Chg}}^{\mathrm{PEV}}(k)+\Delta I_{\mathrm{Chg}-\mathrm{adj}}^{\mathrm{PEV}}(k) \\
& \Delta I_{\mathrm{Chg}-\mathrm{adj}}^{\mathrm{PEV}}(k)=\frac{C^{\mathrm{PEV}} \times F_{\text {Time }} \times\left\{\operatorname{SoC}_{\text {ref }}^{\mathrm{PEV}}(k)-\mathrm{SoC}_{\text {act }}^{\mathrm{PEV}}(k)\right\}}{T_{\text {adj }}} \\
& \operatorname{SoC}_{\text {act }}^{\mathrm{PEV}}(k)=\operatorname{SoC}_{\text {act }}^{\mathrm{PEV}}(k-1)+\frac{I_{\mathrm{Chg}}^{\mathrm{PEV}}(k) \times \Delta t}{C^{\mathrm{PEV}} \times F_{\text {Time }}}
\end{aligned}
$$

where, $I_{\text {Chg-adj }}^{\mathrm{PEV}}(k)$ is the adjusted charging rate, $\Delta I_{\text {Chg-adj }}^{\mathrm{PEV}}(k)$ is the amount of adjustment, and $T_{\text {adj }}$ is a time period for accomplishing the adjustment for minimizing the deviation 
between the actual $\mathrm{SoC}, \mathrm{SoC}_{\mathrm{act}}^{\mathrm{PEV}}$ and the reference, $\mathrm{SoC}$ $\mathrm{SoC}_{\text {ref }}^{\mathrm{PEV}}$. To account for the deviation between the actual SoC and the reference SoC, the PEV charging current may experience high step changes. A rate-limiter is deployed to avoid a high step change in PEV charging current, as given below.

$$
I_{\text {Chg-adj-R }}^{\mathrm{PEV}}(k)=I_{\mathrm{Chg-adj-R}}^{\mathrm{PEV}}(k-1)+\frac{I_{\mathrm{Chg} \text {-adj }}^{\mathrm{PEV}}(k)-I_{\mathrm{Chg-adj}-\mathrm{R}}^{\mathrm{PEV}}(k-1)}{n_{\text {step }}}
$$

where, $I_{\text {Chg-adj-R }}^{\mathrm{PEV}}$ is the rate limited PEV charging current and $n_{\text {step }}$ is the number of steps to limit the rate.

If such an adjustment is made in the charging rate, an effective utilization of the PEV battery capacity can be accomplished. Fig. 4 shows PEV battery SoC profile that experiences intermittency due to cloud shadow and unavailability of the PEV battery due to an incidental travel. If no adjustment of the charging current is performed, PEV battery capacity is left unused. However, if an appropriate adjustment is carried out using (7), a better utilization of the PEV battery is possible.

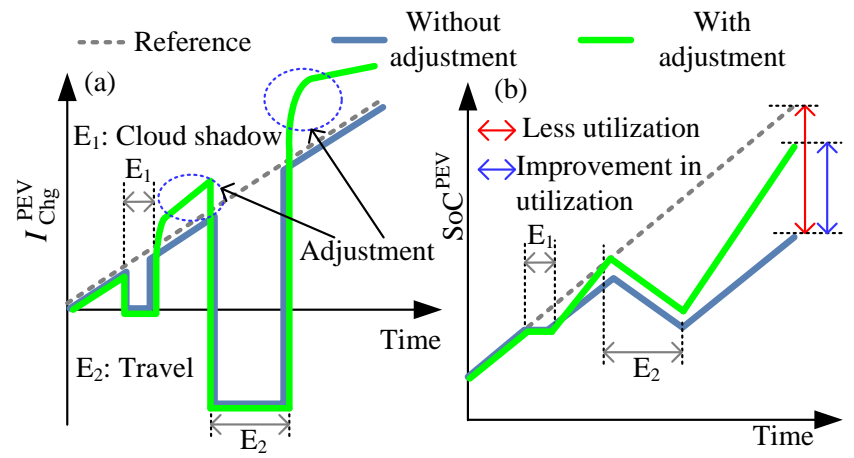

Fig. 4. Adjustment of PEV charging current for better utilization of PEV battery capacity. (a) PEV charging current. (b) PEV SoC.

Similar adjustments will have to be made for the PEV battery discharge current to account for the deviation between the reference SoC obtained using (5), and the actual SoC. Such deviations can be caused by any incidental travel related capacity discharge, any event requiring a short term high discharge, such as supporting a voltage dip, etc.

\section{A Control Strategy for PEV Charging/Discharging}

The control flowchart for the proposed strategy is shown in Fig. 5.The PEV management system continuously monitors the PCC net power $P_{\mathrm{PCC}}$.If a reverse power flow at the PCC, greater than a threshold is experienced, the PEV battery is charged with the surplus PV power. However, if a sudden decrease in PV power is found, the PEV battery is put into a Short-Term Discharge (STD) mode and discharged to provide compensation for sudden decrease in PV output, as shown in Fig. 5(a). To account for any deviation between the reference SoC and the actual SoC of the PEV battery, the charging current is adjusted. Such deviations can be caused by a travel causing battery capacity discharge, unavailability of surplus PV power due to cloud shadow, or discharging of PEV battery in short-term discharge mode. Charging operation is performed using the adjusted and rate-limited charging current command.
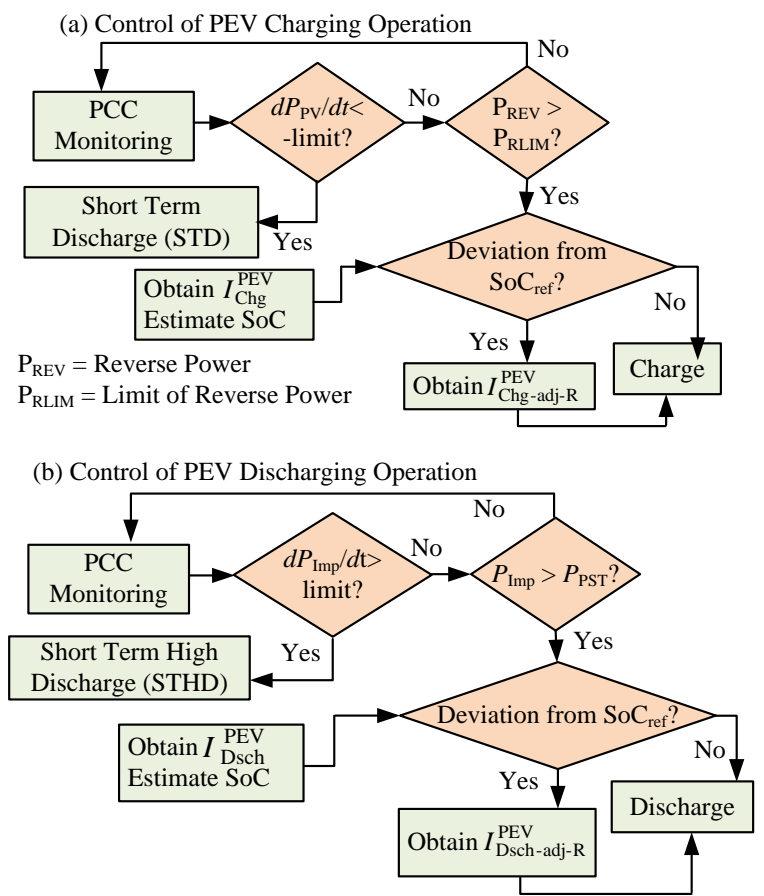

Fig. 5. Control of PEV battery for V2G application. (a) Charging operation. (b) Discharging operation.

PEV discharge operation is performed to provide a peak load support. If the power import from grid, $P_{\mathrm{Imp}}$, exceeds the threshold of peak-shaving load, $P_{\mathrm{PS}}$, discharge operation is performed. In case there is an event that causes a sudden increase in $P_{\mathrm{Imp}}$, such as a motor start, the PEV battery is put into a Short-Term High Discharge (STHD) mode, as shown in Fig. 5(b). To account for the deviation in SoC created by the difference between the reference demand curve and actual demand, the STHD operation, and any travel, the discharge rate is adjusted and rate-limited before issuing the discharge command.

\section{CASE STUdies}

A distribution network containing medium and low voltage feeders has been extracted from a New South Wales Distribution system in Australia to investigate the applicability of the proposed mitigation strategy. This is an $80 \mathrm{~km}$ long 11 $\mathrm{kV}$ rural network containing over $7011 \mathrm{kV}$ nodes. A single line diagram of the network is shown in Fig. 6. One of the LV feeders is shown in detail in a dashed circular shape. It is a0.4 $\mathrm{kV} 3$ phase $\mathrm{LV}$ feeder constructed using a $7 \times 3.00 \mathrm{~mm}$ All Aluminum Conductor(7/3.00 AAC) with $\mathrm{R} / \mathrm{X}$ ratio of 2.5 (typically Australian LV networks have R/X ratio over 1.0 and can be higher than 4.5 with LV Aerial Bundled Conductor.) The feeder supplies power to 18 customers, 6 customers per phase. Although, a balanced customer distribution has been considered in this paper, unbalanced customer distribution is observed in LV feeders in Australia and this can pose new challenges for balancing in the presence of PV and PEV. Specifications of the LV feeder used for simulation are presented in Table I. For the analysis of PV and PEV impacts, 
the LV feeders connected to bus 29, 30 and 31 have considered forming a cluster where all the customers have rooftop PV and PEV.

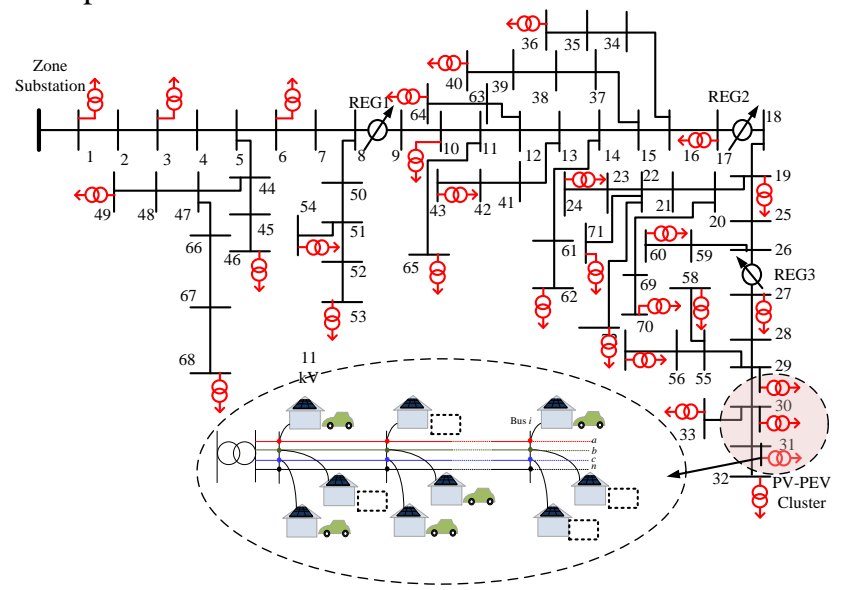

Fig. 6. A practical distribution system in Australia.

The load profile data is obtained from a real load demand curve captured by an Australian distribution utility and the PV data corresponds to a PV output profile captured by the Commonwealth Scientific and Industrial Research Organisation (CSIRO) on the $5^{\text {th }}$ February, 2011. The PV system sizes at the residential households were limited within $4 \mathrm{~kW}$ and operated at unity power factor. PEVs are simulated using specifications given in Table II, based on a Nissan Leaf[23]. PEV batteries are modelled by mapping the nonlinear relationship between $\mathrm{SoC}$ and battery voltage incorporating the effect of internal resistance [22] to account for the round-trip efficiency of the battery, which is $77 \%$ to $81 \%$ for a typical lead-acid battery[24]. The 0.95 charger efficiency [25] is considered for the on-board charger of the PEV which is used normally for home charging and it does not include battery losses. The user specified minimum SoC of the PEV battery is determined using (6) based on a $30 \mathrm{~km}$ per day travel and an incidental $10 \mathrm{~km}$ travel. The $30 \mathrm{~km}$ per day travel assumption is based on the driving habit statistics reported in [26].

TABLE I

Data OF A TYPICAL Australian Low Voltage FeEdER

\begin{tabular}{|c|c|}
\hline Feeder Length (metre) & \multirow{6}{*}{$\begin{array}{l}240 \\
40 \\
160 \mathrm{kVA}, 3 \mathrm{ph} \\
2.2 \mathrm{~kW} \text { at } 0.95 \mathrm{PF} \text { (lag) } \\
4 \mathrm{~kW} \\
\text { Kyocera /SMA Sunnyboy }\end{array}$} \\
\hline Pole to Pole Distance (metre) & \\
\hline MV/LV Transformer & \\
\hline Maximum Load per Customer & \\
\hline PV Size $(\mathrm{kW})$ & \\
\hline PV Module and Inverter Make & \\
\hline \multicolumn{2}{|c|}{$\begin{array}{c}\text { TABLE II } \\
\text { PEV DATA USED FOR SIMULATION } \\
\end{array}$} \\
\hline PEV Make and Model & Nissan Leaf \\
\hline Rated Battery Capacity & $60 \mathrm{Ah} / 24 \mathrm{kWh}$ \\
\hline Voltage & $364 \mathrm{~V}$ \\
\hline PEV Fuel Economy & $0.3 \mathrm{kWh} / \mathrm{mile}$ \\
\hline Charger Efficiency & 0.95 \\
\hline
\end{tabular}

Several simulation scenarios have been set up for the analysis of the PV impact mitigation and grid support by PEV. To mitigate the voltage rise impact using the battery storage device of the PEV battery, the PEV needs to be parked at home. According to the statistics presented in [18], the probability of a PEV to stay at home during the daytime of a weekday is over 0.5 . Based on this, 50\% of the PEVs, i.e., 27 out of 54 PEVs in the entire PV-PEV cluster are assumed to be parked and plugged in at home to be charged from the surplus PV power. At first, a scenario is considered where none of the 50\% of PEVs staying at home go for a travel during the daytime charging period, and therefore all the PEVs can be charged without any intervention. The load and PV output profile for a customer in the PV-PEV cluster is shown in Fig. 7(a), where the periods of charging and discharging are identified using $T_{\text {Chg }}$ and $T_{\text {Dsch }}$ respectively. Using the PEV charging pattern in (1), obtained from the parameters based on (2)-(3), the power consumption profile for PEV battery charging is shown in Fig. 7(b).
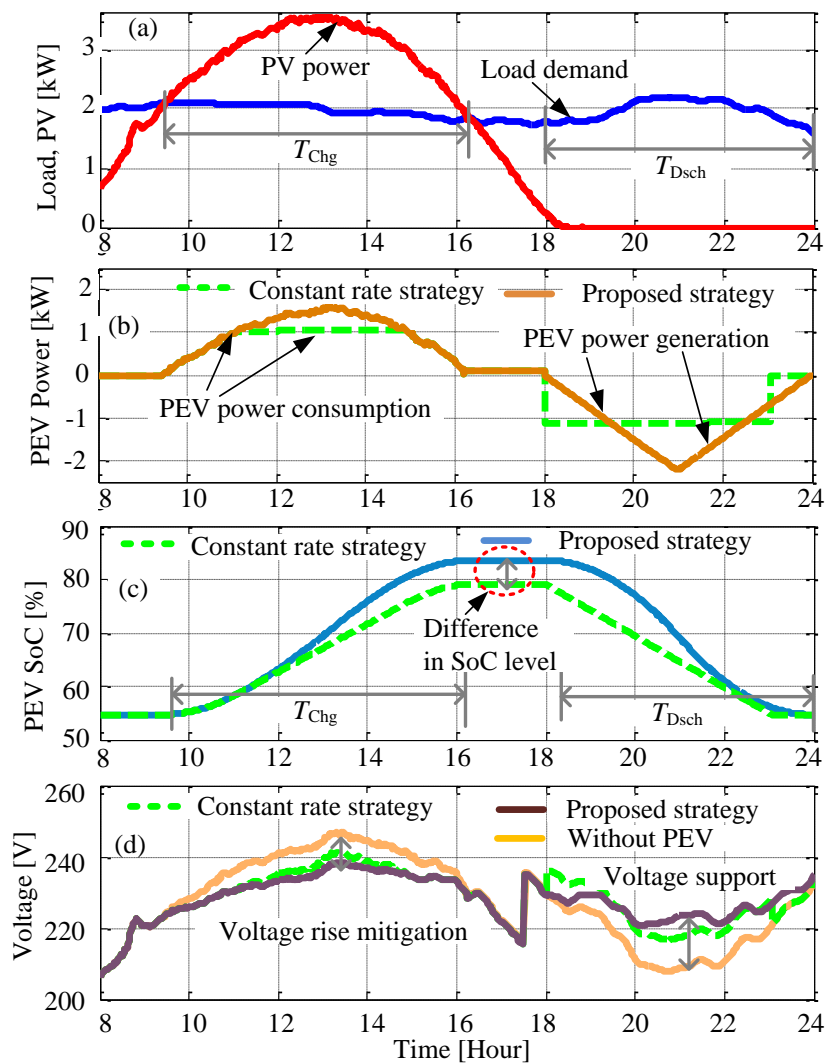

Fig. 7. PV impact mitigation and grid support using PEV battery. (a) Load demand and PV generation. (b) PEV storage power profile. (c) PEV SoC profile. (d) Voltage profile at the LV side of the MV/LV substation.

The power consumed by the PEV battery increases from zero at the start of the reverse power flow period, reaches the peak level at the midday and decreases to zero at the end of the reverse power flow period. If the PEV battery is charged using a constant rate, then the power consumed by the PEV battery would be either be a constant (based on the charging rate and battery voltage), or equal to the surplus PV power available at the PCC. Fig. 7(b) shows the power profile of the PEV battery based on a constant charging rate and based on the proposed charging strategy. It is observed that at midday when surplus power is at its maximum and the PV impact is most significant, then the charging power with the proposed charging strategy (approximately $1.6 \mathrm{~kW}$ ) is higher than that from the constant charging rate (approximately $1.0 \mathrm{~kW}$ ). During the evening peak demand period, the load support using the proposed strategy is also higher than that from the constant discharge strategy. 
The SoC profiles of the PEV battery with the proposed strategy is compared in Fig. 7(c) with the SoC profile based on a constant charging/discharging rate strategy. With the proposed strategy the SoC level at the end of the charging period is $83 \%$, which is higher than the SoC level $(79 \%)$ obtained based on the constant rate strategy. This is caused by a higher amount of power consumption in the midday period according to the proposed strategy as compared to the constant rate charging strategy. The voltage profile at the LV side of an $\mathrm{MV} / \mathrm{LV}$ substation transformer in the PV-PEV cluster is shown in Fig. 7(d) that shows the effect of PEV on voltage rise mitigation during midday and peak load support in the evening. As shown in Fig. 7(d), the voltage profile with the constant rate strategy mitigates voltage rise and provides voltage support by a lesser amount (i.e. $2.9 \mathrm{~V}$ for voltage rise, and $4 \mathrm{~V}$ for voltage support) compared to the proposed strategy.

As the assumption of $50 \%$ of the PEVs parked at home during midday is not certain, a Monte Carlo test [27]is conducted by drawing 1000 random samples from $1 \%$ to $100 \%$ of the total number of PEVs using uniform distribution. The locations of PEVs parked at home in the PV-PEV cluster are also selected randomly. Three phase voltages at the same LV substation bus are plotted in Fig. 8 for different percentages of PEVs parked at home.

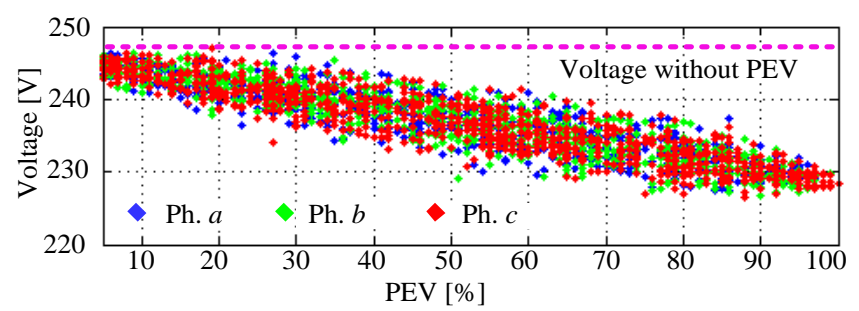

Fig. 8. A Monte Carlo test on the effect of the change in percentage of PEVs parked at home on voltage rise mitigation.

It is observed that with less than $40 \%$ of PEVs present, the mitigation of voltage rise is not significant for all the random samples; with over 40\% PEVs present, the level of voltage rise mitigation is significant for all the samples.

As the PEVs are mainly intended for travel, the impact of a travel within the period of voltage rise mitigation and grid support has to be considered in the analysis. A likely event of an incidental travel by a PEV during the charging operation will have two impacts: one is the PEV will not be plugged-in at home for mitigating the PV impacts, and the other is the PEV SoC level will be reduced due to the energy spent in driving. To investigate the impacts of these issues on voltage rise mitigation and grid voltage support, acase is considered where one-third of the PEVs (randomly selected) from each of the LV feeders in the PV-PEV cluster travel for a $10 \mathrm{~km}$ drive and remain absent for 30 minutes in the day time. The charging power profiles and $\mathrm{SoC}$ profiles corresponding to a PEV that stays at home all the time and a PEV that travels a short distance are shown in Fig. 9(a) and 9(b). The PEV that travels is not charged for a 30 minute interval as indicated in Fig. 9(a) and due to the energy lost in the travel, the SoC level is reduced, as shown in Fig. 9(b), when it returns home and is plugged-in to the charging system.
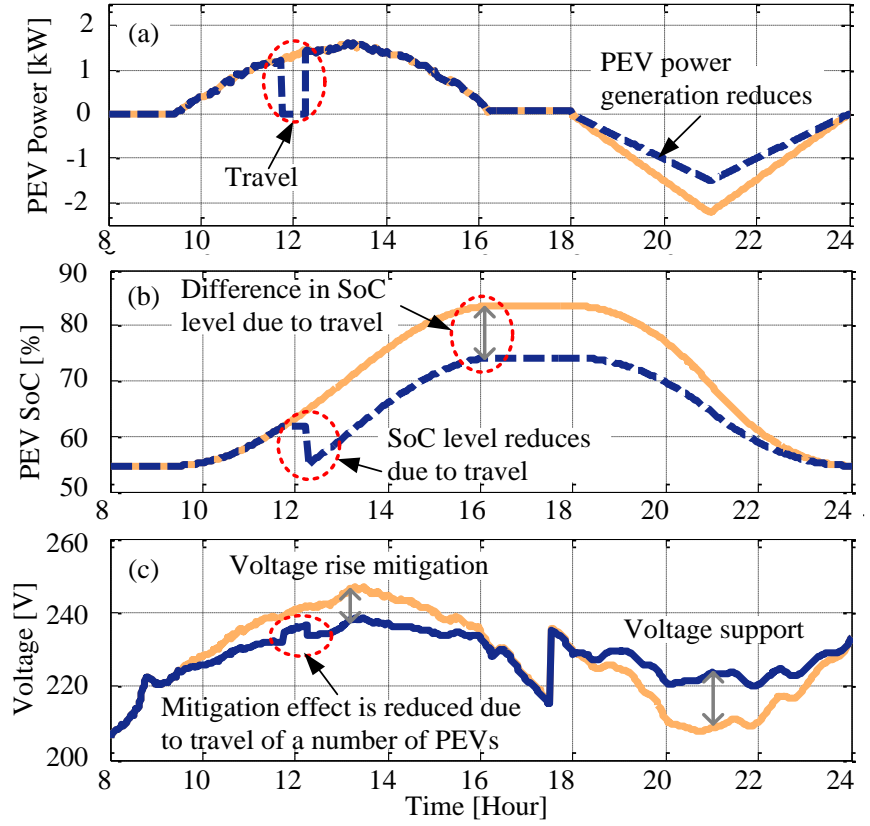

Fig. 9. PV impact mitigation and grid support using PEV battery when some of the PEVs are absent during a travel. (a) PEV storage power profile. (b) PEV SoC profile. (c) Voltage profile at the LV side of the MV/LV substation.

Although the dynamic adjustment feature of the proposed charging strategy endeavors to make up for the charge lost in driving, the amount of the surplus PV power is not sufficient. Therefore, the SoC level of the PEV that travels is 74\%, which is lower than that for the PEV that is plugged-in all the time. As the PEV that travels stores less amount of energy compared to the PEV that stays for the whole charging time, the set of the discharge parameters used in (5) will be different for this PEV. The discharge power profiles in Fig. 9(b) shows the differences in power generated by the two PEVs due to the differences in their stored energy. The voltage profile at the LV side of the same substation bus is shown in Fig. 9(c). It is observed that the voltage is increased for a 30 minute period while one-third of the PEVs in the cluster are being used for travel.

Another case with travel is investigated where an additional set of PEVs go for a $15 \mathrm{~km}$ travel prior to the start of the evening peak as indicated in Fig. 10(a), leaving the SoC levels of those PEVs depleted to $72 \%$ as shown in Fig. 10(b). Therefore, two-third of the PEVs has less stored energy for evening peak support. Based on the stored energy, the discharge parameters are recalculated using the proposed method. The power generated by the PEVs having less stored energy is reduced as shown in Fig. 10(b). As the major part of the PEVs have less stored energy and provides less amount of power for evening peak support, the voltage support in the evening load period is reduced as shown in Fig. 10(c).

To investigate the effectiveness of the charging rate adjustment, another PV output profile captured by CSIRO on the $9^{\text {th }}$ February 2011 with cloud induced fluctuations in the PV output is considered, as shown in Fig. 11(a). The event of the $10 \mathrm{~km}$ travel with 30 minutes absence considered in Fig. 9 is also included so that the effect of the charging rate adjustment after both types of events can be investigated. The capacity at the start of the charging period is considered to be 
$85 \%$, which is higher than the user specified minimum (54\%), so that effect of the charging rate adjustment can be illustrated with the available surplus PV power. The PV inverter output with the V2G functionality of the PEV in Fig. 11(a) shows that the fluctuations caused by passing cloud is mitigated by a short-term discharge of the PEV battery. It is observed from the PEV battery power profile in Fig. 11(b) that each shortterm discharge event or each time the PEV is not charged (when travelling) is followed by an adjustment of the charging rate to make-up for the charge lost or not accumulated. This adjustment leads to an increase of the power consumption of the PEV battery as indicated by the dashed circles in Fig. 11(b). Therefore, the SoC of the PEV battery can reach a higher level than the $\mathrm{SoC}$ without adjustment, as shown in Fig. 11(c).
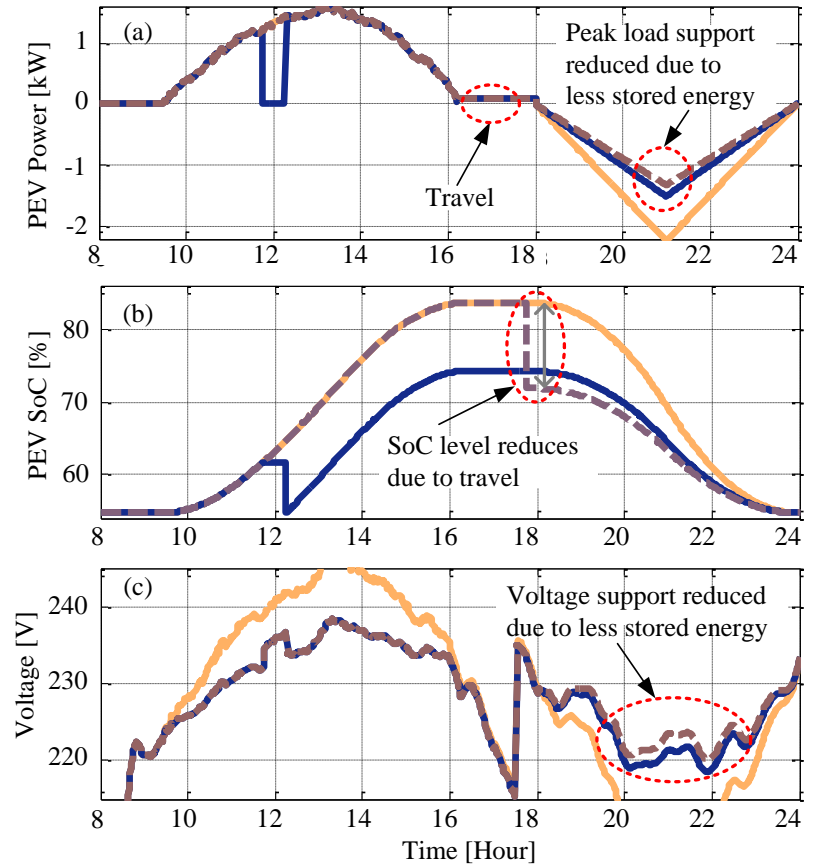

Fig. 10. PV impact mitigation and grid support using PEV battery when an additional set of the PEVs are absent during a travel before the start of the evening peak. (a) PEV storage power profile. (b) PEV SoC profile. (c) Voltage profile at the LV side of the MV/LV substation.

The rest $50 \%$ of the PEVs in the PV-PEV cluster that were not parked at home are likely to return by the evening and get charged for the next day's travel. As the household load demand itself reaches its peak in the evening, it would be wise to charge the PEVs in the late night till early morning rather than charging in the evening which will impose additional stress on the system. To keep the PEV charging load at a low level during the periods when the system load demand is still decreasing from the peak level and when the load demand is again increasing due to early morning household activities, the proposed approach uses a trapezoidal charging pattern, as shown in Fig. 12.

This allows charging the PEV batteries at the maximum level during the period when household load demand is at its base level. Based on the amount of charge to be stored for next day's travel and the length of the charging period, (2)-(3) are used to determine the charging parameters and then charging is performed based on the charging currents determined using
(1). The PEV charging power profile for late night charging from 23 hours to 7 hours to store the charge $(5.63 \mathrm{Ah})$ equivalent to one days travel $(30 \mathrm{~km})$ is shown in Fig. 12(a). It is observed that using the proposed charging pattern, the PEV battery is charged at the maximum level when the household demand is at the minimum level, as shown in Fig. 12(b), and therefore the stress on the system exerted by the PEV charging load is reduced.
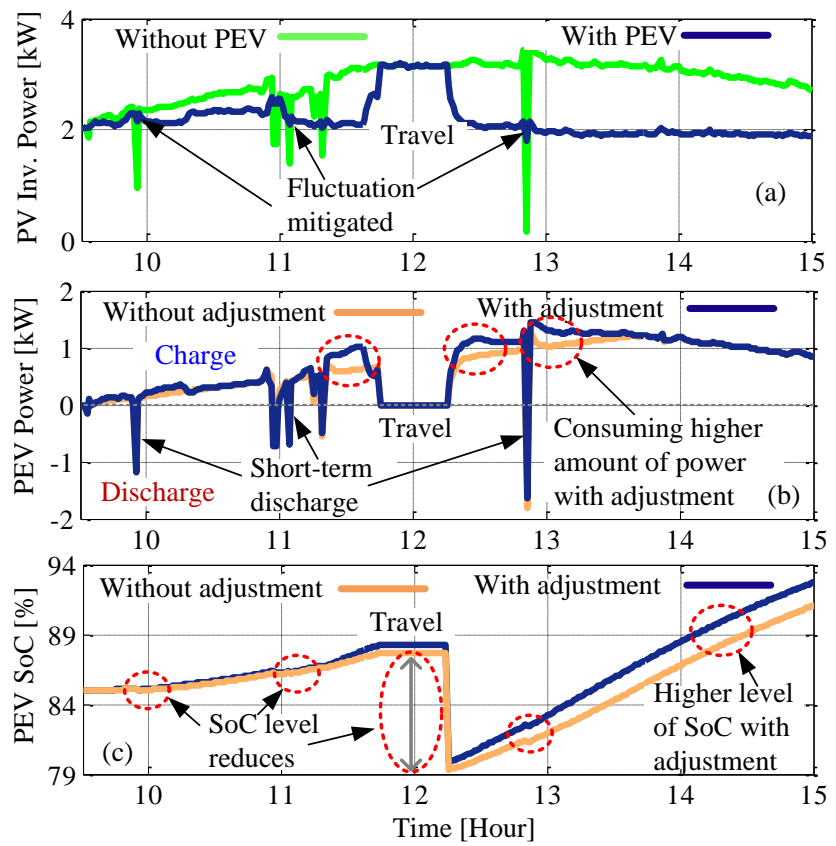

Fig. 11. The effectiveness of charging rate adjustment in the events of shortterm discharge for fluctuation mitigation and travel. (a) PV inverter power profile with and without PEV V2G functionality. (b) PEV storage power profile. (c) PEV SoC profile.
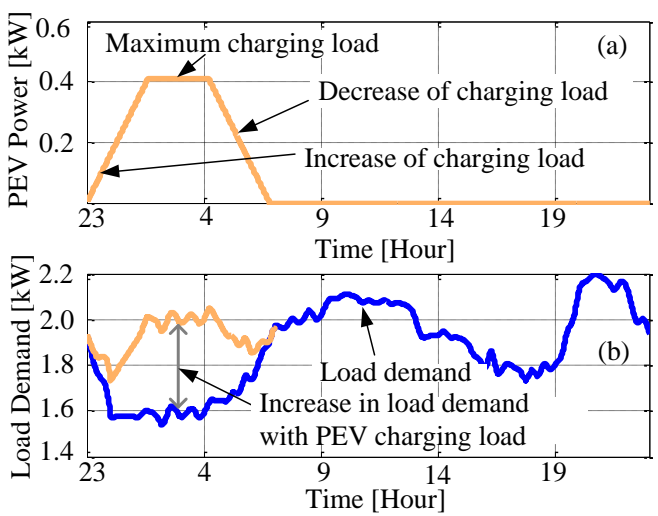

Fig. 12. Late night PEV charging. (a) PEV storage power profile. (b) Load demand profile with PEV charging load.

\section{CONCLUSION}

This paper has developed a charging strategy, to effectively store energy in the PEV batteries taking into account the limited PEV battery capacity, for the mitigation of voltage rise and reverse power flow caused by surplus solar PV power during mid-day. The paper has also proposed a discharging strategy for the use of the stored energy in PEV batteries for the distribution network voltage support, especially during evening peak load period, while ensuring that there is sufficient remaining capacity in the batteries in case there is a 
need for travel prior to the next charging event. The proposed strategy provides the advantage of controlling the shape of the charging/discharging profile to match the general trend of solar PV power generation and peak load profile as compared to the traditional constant charging/discharging strategy. Therefore, in the midday when the PV impact is most severe, the proposed strategy can provide a better mitigation action as compared to the constant rate charging strategy. Similarly, the proposed strategy is able to provide a better voltage support during the occurrence of the maximum evening load compared to the constant rate discharging strategy. To account for the interventions in charging/discharging operation caused by any travel of the PEV, the proposed strategy adjusts the charging/discharging rates dynamically based on a reference SoC so that the limited available capacity of the PEV battery is utilized in a wise manner. Simulation results show that proposed strategy can provide better mitigation and voltage support as compared to a constant rate strategy. The simulation results also suggest that even when some PEVs in a feeder are not being plugged in at home, the remaining PEVs that are connected to the grid may still offer appreciable benefits in terms of solar PV impact mitigation and network voltage support. It is envisaged that the proposed strategy will provide some economic benefits, such as reducing the evening peak load and mitigating the PV impacts using synergetic PEV batteries. However, its financial implications need to be assessed based on the potential energy loss in the charging and discharging of the PEV batteries, its impact on the PEV battery's life-cycle, and the potential impact that electricity tariff can cause on the proposed strategy.

\section{REFERENCES}

[1] O. Erdinc, N. G. Paterakis, T. D. P. Mendes, A. G. Bakirtzis, and J. P. S. Catalao, "Smart Household Operation Considering Bi-Directional EV and ESS Utilization by Real-Time Pricing-Based DR," IEEE Transactions on Smart Grid, vol. PP, pp. 1-1, 2014.

[2] J. M. Foster, G. Trevino, M. Kuss, and M. C. Caramanis, "Plug-In Electric Vehicle and Voltage Support for Distributed Solar: Theory and Application," IEEE Systems Journal vol. 7, pp. 881-888, 2013.

[3] L. Igualada, C. Corchero, M. Cruz-Zambrano, and F. J. Heredia, "Optimal Energy Management for a Residential Microgrid Including a Vehicle-toGrid System,", IEEE Transactions on Smart Grid, vol. 5, pp. 2163-2172, 2014.

[4] J. Lassila, J. Haakana, V. Tikka, and J. Partanen, "Methodology to Analyze the Economic Effects of Electric Cars as Energy Storages," EEE Transactions on Smart Grid, vol. 3, pp. 506-516, 2012.

[5] C. Pang, P. Dutta, and M. Kezunovic, "BEVs/PHEVs as Dispersed Energy Storage for V2B Uses in the Smart Grid," IEEE Transactions on Smart Grid, vol. 3, pp. 473-482, 2012.

[6] A. Y. Saber and G. K. Venayagamoorthy, "Plug-in Vehicles and Renewable Energy Sources for Cost and Emission Reductions," IEEE Transactions on Industrial Electronics vol. 58, pp. 1229-1238, 2011.

[7] M. Singh, P. Kumar, and I. Kar, "A Multi Charging Station for Electric Vehicles and Its Utilization for Load Management and the Grid Support," IEEE Transactions on Smart Grid, vol. 4, pp. 1026-1037, 2013.

[8] D. P. Tuttle and R. Baldick, "The Evolution of Plug-In Electric VehicleGrid Interactions," IEEE Transactions on Smart Grid, vol. 3, pp. 500505, 2012

[9] M. Yilmaz and P. T. Krein, "Review of the Impact of Vehicle-to-Grid Technologies on Distribution Systems and Utility Interfaces," IEEE Transactions on Power Electronics, vol. 28, pp. 5673-5689, 2013.

[10]K. Clement-Nyns, E. Haesen, and J. Driesen, "The Impact of Charging Plug-In Hybrid Electric Vehicles on a Residential Distribution Grid," IEEE Transactions on Power Systems, vol. 25, pp. 371-380, 2010.
[11]Q. Kejun, Z. Chengke, M. Allan, and Y. Yue, "Modeling of Load Demand Due to EV Battery Charging in Distribution Systems," IEEE Transactions on Power Systems, vol. 26, pp. 802-810, 2011.

[12]H. Sikai and D. Infield, "The impact of domestic Plug-in Hybrid Electric Vehicles on power distribution system loads," in International Conference on Power System Technology (POWERCON) Hangzhou, China, 24-28 Oct. 2010, pp. 1-7.

[13] A. Canova, L. Giaccone, F. Spertino, and M. Tartaglia, "Electrical Impact of Photovoltaic Plant in Distributed Network," IEEE Transactions on Industry Applications vol. 45, pp. 341-347, 2009.

[14]F. Spertino, P. D. Leo, and V. Cocina, "Which are the constraints to the photovoltaic grid-parity in the main European markets?," Solar Energy, vol. 105, pp. 390-400, 7// 2014.

[15] R. Tonkoski, L. A. C. Lopes, and T. H. M. El-Fouly, "Coordinated Active Power Curtailment of Grid Connected PV Inverters for Overvoltage Prevention," IEEE Transactions on Sustainable Energy, vol. 2, pp. 139147, 2011.

[16]E. Demirok, P. González, K. H. B. Frederiksen, D. Sera, P. Rodriguez, and R. Teodorescu, "Local Reactive Power Control Methods for Overvoltage Prevention of Distributed Solar Inverters in Low-Voltage Grids," IEEE Journal of Photovoltaics vol. 1, pp. 174-182, 2011.

[17]J. Tomić and W. Kempton, "Using fleets of electric-drive vehicles for grid support," Journal of Power Sources, vol. 168, pp. 459-468, 2007.

[18]W. Di, D. C. Aliprantis, and K. Gkritza, "Electric Energy and Power Consumption by Light-Duty Plug-In Electric Vehicles," IEEE Transactions on Power Systems, vol. 26, pp. 738-746, 2011.

[19] J. R. Aguero, P. Chongfuangprinya, S. Shengnan, X. Le, F. Jahanbakhsh, and H. L. Willis, "Integration of Plug-in Electric Vehicles and distributed energy resources on power distribution systems," in IEEE International Electric Vehicle Conference (IEVC), Greenville, SC, USA, 4-8 March 2012 , pp. 1-7.

[20]F. Marra, G. Y. Yang, C. Traeholt, E. Larsen, J. Ostergaard, B. Blazic, et al., "EV Charging Facilities and Their Application in LV Feeders With Photovoltaics," IEEE Transactions on Smart Grid, vol. 4, pp. 1533-1540, 2013.

[21]F. Marra, G. Y. Yang, Y. T. Fawzy, C. Traeholt, E. Larsen, R. GarciaValle, et al., "Improvement of Local Voltage in Feeders With Photovoltaic Using Electric Vehicles," IEEE Transactions on Power Systems, vol. 28, pp. 3515-3516, 2013.

[22]M. J. E. Alam, K. M. Muttaqi, and D. Sutanto, "Mitigation of Rooftop Solar PV Impacts and Evening Peak Support by Managing Available Capacity of Distributed Energy Storage Systems," IEEE Transactions on Power Systems, vol. 28, pp. 3874-3884, November 2013.

[23](10 Feb. 2014). 2011 Nissan Leaf - VIN 0356 Advanced Vehicle Testing Beginning-of-Test Battery Testing Results [Online]. Available: http://www1.eere.energy.gov/vehiclesandfuels/avta/pdfs/fsev/battery_leaf 0356.pdf

[24]G. M. Masters, Renewable and Efficient Electric Power Systems. New Jersey: Wiley-IEEE Press, 2004.

[25](2010). Eltek Valere Installation Guide: Electric Vehicle Power Chargers, $3 k W \quad H E$ [Online]. Available: http://evolveelectrics.com/PDF/Eltek/Eltek\%20Guide\%20IP20.pdf

[26]J. Taylor, J. W. Smith, and R. Dugan, "Distribution modeling requirements for integration of $\mathrm{PV}, \mathrm{PEV}$, and storage in a smart grid environment," in IEEE Power and Energy Society General Meeting, Detroit, MI, USA, 24-29 July 2011, pp. 1-6.

[27]S. Wencong and C. Mo-Yuen, "Evaluation on intelligent energy management system for PHEVs/PEVs using Monte Carlo method," in 4th International Conference on Electric Utility Deregulation and Restructuring and Power Technologies, Weihai, Shandong, China, 6-9 July 2011, pp. 1675-1680.

\section{BIOGRAPHIES}

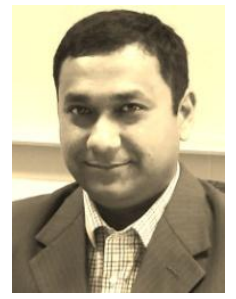

M J E Alam (M'14) received B.Sc. and M.Sc. Degree in Electrical and Electronic Engineering from Bangladesh University of Engineering and Technology, Dhaka, Bangladesh, in 2005 and 2009, respectively. In 2014, he obtained $\mathrm{PhD}$ degree in electrical engineering from the University of Wollongong, New South Wales, Australia, where he worked as an Associate Research Fellow. Currently he is working as a Postdoctoral Research 
Fellow at Global Change Institute, The University of Queensland, Australia His research interest includes modeling and analysis of power systems with focus on renewable energy resources. He has also worked in the electric power industry in Bangladesh.

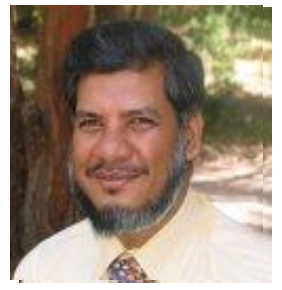

K M Muttaqi (M'01, SM'05) received the B.Sc. degree in electrical and electronic engineering from Bangladesh University of Engineering and Technology (BUET), Dhaka, Bangladesh in 1993, the M.Eng.Sc. degree in electrical engineering from University of Malaya, Kuala Lumpur, Malaysia in 1996 and the Ph.D. degree in Electrical Engineering from Multimedia University, Selangor, Malaysia in 2001. Currently, he is an Associate Professor at the School of Electrical, Computer, and Telecommunications Engineering, and member of Australian Power Quality and Reliability (APQRC) at the University of Wollongong, Wollongong, Australia. He was associated with the University of Tasmania, Hobart, Australia as a Research Fellow/Lecturer/Senior Lecturer from 2002 to 2007, and with the Queensland University of Technology, Brisbane, Australia as a Research Fellow from 2000 to 2002. Previously, he also worked for Multimedia University as a Lecturer for three years. He has more than 18 years of academic experience and authored or coauthored 230 papers in international journals and conference proceedings. His research interests include distributed generation, renewable energy, electrical vehicles, smart-grid, power system planning and emergency control. Dr. Muttaqi is an Associate Editor of the IEEE TRANSACTIONS ON INDUSTRY APPLICATIONS.

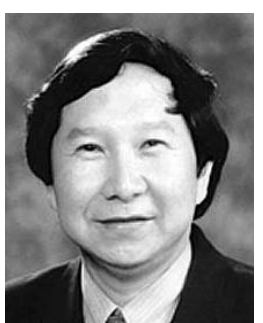

D Sutanto (SM'89) obtained his BEng. (Hons) and $\mathrm{PhD}$ from the University of Western Australia. He is presently the Professor of Power Engineering at the University of Wollongong, Australia. His research interests include power system planning, analysis and harmonics, FACTS and Battery Energy Storage systems. He is a Senior Member of IEEE. He is currently the IEEE IAS Area Chair for Region 10 (East South Asia and Pacific). 